\title{
Plasmid Encoded Toluene and Xylene Degradation by Phyllosphere Bacteria
}

\author{
Undugoda LJS ${ }^{1 *}$, Kandisa RV ${ }^{2}$, Kannangara $\mathbf{S}^{3}$ and Sirisena DM
}

${ }^{1}$ Department of Biosystems Technology, Faculty of Technology, University of Sri Jayewardenepura, Sri Lanka

${ }^{2}$ GITAM Institute of Technology, GITAM University, Visakhapatnam, Andhra Pradesh, India

${ }^{3}$ Department of Botany, Faculty of science, University of Kelaniya, Kelaniya, Sri Lanka

\begin{abstract}
Air pollution by monoaromatic hydrocarbons (MAH) is a highly concerned great threat in modern world due to the high carcinogenicity and genotoxicity to all living beings. Most of these MAH releasing processes are oil refining processes and vehicular emission. These air trapped pollutants deposit on ground level and phyllosphere takes special place as a ground level exposure surface for these pollutants. Continuous deposition lead to make a MAH degrading microbial consortium in the phyllosphere and these microorganisms can be used as an efficient bioremediators in remediating MAH contaminants which is an environmental friendly solution compared to chemical remediations. The phyllosphere of plant species Ixora chinensis, Ervatamia divaricata, Hibiscus rosa-sinensis and Amaranthus cruentus which are highly abundant along the roadsides of polluted areas in Sri Lanka are rich with several species of bacteria belong to many genera and they were able to degrade toluene and xylene efficiently. The species of Alcaligenes feacalis, Alcaligenes DN25 Bacillus cereus and Bacillus methylotrophicus were able to degrade toluene and xylene efficiently. All these strains harbor plasmids conferring them resistance to ampicillin. Curing of the plasmids of $A$. feacalis and Alcaligenes sp. DN25 drastically reduced the ability in degrading these toluene and xylene. Upon transformation of plasmids of these two Alcaligenes sp. into E. coli JM109 enabled it to degrade the two hydrocarbons efficiently. But transformation and curing process of two Bacillus sp. into the E. coli JM109 was unsuccessful. Plasmid encoded toluene and xylene degradation of two Alcaligenes sp. suggested the presence of required catabolic genes in these plasmids. PCR amplification with degenerate primers and comparison of their nucleotide sequences with Genbank sequences indicated that plasmids of $A$. feacalis, Alcaligenes sp. DN25 and $B$. cereus harbor the genes $x y / Q$ involved in toluene and xylene degradation. RFLP and nucleotide sequence comparisons of $x y \mid Q$ amplicons revealed that both of these genes in two bacterial strains ( $A$. feacalis and Alcaligenes sp. DN25) are homologous. But that was heterologous to the $x y / Q$ gene of $B$. cereus. Hence the results clearly showed the potential of $A$. feacalis, Alcaligenes sp. DN25 and $B$. cereus in degrading toluene and xylene and also the potential of using them in remediating aromatic hydrocarbonic contaminants.
\end{abstract}

Keywords: Bioremediation; Phyllosphere; Bacillus sp.; Catabolic plasmid; RFLP pattern

\section{Introduction}

Toluene and xylene are major air pollutants which give great risk to all living beings due to their high carcinogenicity and genotoxicity [1]. Plant leaf surfaces are the major exposing surfaces to these aromatic hydrocarbons when they deposit on ground level by wet and dry deposition. These plant surfaces are called phyllosphere and it is a great niche to microorganisms belongs to several genera of bacteria, fungi, algae, protozoans and nematodes. Out of them bacteria and fungi are the predominant microorganisms and those who abundant in the phyllosphere of polluted sites had special ability in aromatic hydrocarbon degradation. The results of Undugoda et al. [2], revealed phyllosphere fungi and bacteria isolated from polluted sites of Sri Lanka had naphthalene and phenanthrene like polyaromatic hydrocarbon degradation ability. Aromatic hydrocarbon degradation ability of most of bacteria is a plasmid encoded character. According to the results of Assinder and Williams, 1990 TOL plasmid pWW0 of Pseudomonas putida harbored genes which can encode enzymes to degrade toluene and xylene. $X y l$ genes harboured in this TOL plasmid pWWO are organized into two operons as the upper and meta operons which are positively regulated by $x y l R$ and $x y l S$ genes [3]. Two plasmid-encoded operons account for the entire metabolic process that leads to biodegradation of such aromatic substrates [4]. The upper operon encode the enzymes to convert $\mathrm{m}$-xylene or toluene into 3-methylbenzoate or benzoate, respectively, and the lower operon enzymes determine the conversion of $3 \mathrm{MBz}$ into 3-methylcatechol or benzoate into catechol and its ensuing meta ring cleavage, which ultimately leads to intermediates of the TCA cycle $[5,6]$.
This research was attempted to identify the plasmid encoded toluene and xylene degradation ability of the isolated phyllosphere bacterial species which are highly abundant in the phyllosphere of polluted sites in Sri Lanka. And also availability of toluene and xylene degrading some selected genes in these plasmids of these bacteria was determined and further characterization was done following sequencing and RFLP results.

\section{Materials and Methods}

Aromatic hydrocarbon degrading Alcaligenes faecalis (KT356811), Alcaligenes sp. DN25 (KT356809), Bacillus methilotrophicus (KT356809) and Bacillus cereus (KT356812) were isolated from the leaf samples collected from the four plant species, Ixora chinensis, Ervertamia dervaticata, Amaranthus cruentus and Hibiscus rosasinensis inhabit the five polluted sites, Colombo fort, Maradana, Panchikawattha, Sapugaskanda and Orugodawattha in Sri Lanka [2].

*Corresponding author: Undugoda LJS, Department of Biosystems Technology, University of Kelaniya, Kelaniya, Sri Lanka, Tel: 92649884134; E-mail: lankaundugoda@tech.sjp.ac.lk

Received March 06, 2018; Accepted March 17, 2018; Published March 22, 2018

Citation: Undugoda LJS, Kandisa RV, Kannangara S, Sirisena DM (2018) Plasmid Encoded Toluene and Xylene Degradation by Phyllosphere Bacteria. J Environ Anal Toxicol 8: 559. doi: 10.4172/2161-0525.1000559

Copyright: @ 2018 Undugoda LJS, et al. This is an open-access article distributed under the terms of the Creative Commons Attribution License, which permits unrestricted use, distribution, and reproduction in any medium, provided the original author and source are credited. 
Citation: Undugoda LJS, Kandisa RV, Kannangara S, Sirisena DM (2018) Plasmid Encoded Toluene and Xylene Degradation by Phyllosphere Bacteria. J Environ Anal Toxicol 8: 559. doi: 10.4172/2161-0525.1000559

Page 2 of 4

\section{Plasmid isolation}

$1.5 \mathrm{ml}$ of overnight bacterial culture was spun for 1 minute in a micro-centrifuge to make the pellet. The bacterial pellet was resuspended in $200 \mu \mathrm{l}$ of ice-cold solution containing $0.04 \mathrm{M}$ Trisacetate, $\mathrm{pH} 8.0$ (adjust $\mathrm{pH}$ with glacial acetic acid) and vortexed vigorously. $400 \mu \mathrm{l}$ of lysis buffer (0.05 M Tris, $3 \%$ SDS, pH 12.50, adjusted with $2 \mathrm{~N} \mathrm{NaOH}$ ) was added into each bacterial suspension and mixed well. Then it was incubated at $60-68^{\circ} \mathrm{C}$ for $30-45 \mathrm{~min} .1000 \mu \mathrm{l}$ of phenol/chloroform (1:1) was added into the hot sample and mix gently to complete emulsification. Then the emulsion was centrifuged at $14000 \mathrm{rpm}$ for 2 minutes at $4^{\circ} \mathrm{C}$ in a microfuge. The aqueous upper layer was transferred to a fresh tube. Plasmid DNA was precipitated from the supernatant by adding $600 \mu \mathrm{l}$ of $95 \%$ ethanol at room temperature. The plasmid DNA was dissolved in $100 \mu \mathrm{l}$ of TE ( $\mathrm{pH}$ 8.0) containing $20 \mu \mathrm{g} / \mathrm{ml}$ DNase-free RNase A (pancreatic RNase). The solution was vortexed gently for a few seconds. The plasmid DNA was stored at $-20^{\circ} \mathrm{C}$.

\section{Determination of plasmid based toluene and xylene degradation of selected two bacteria}

Isolated plasmids were transformed to a E. coli JM109 following the method of Sambrook et al. [7] and toluene and xylene degradation ability of transformants were checked using HPLC method described in Undugoda et al. [2]. Then again plasmids of transformants were cured following Undugoda et al. [2], and again their toluene and xylene degradation ability was checked.

\section{PCR amplification of $x y l Q$ and $x y l M$ regions in catabolic plasmid}

The gene sequences of $x y l Q$ gene of $P$. putida pWWO and Pseudomonas migulae (GenBank accession nos NC003350, and NC021250, respectively) have been used to design the degenerate primers to amplify $x y l Q$ gene. Then $x y l M$ gene sequence of $P$. putida pWWO53 (GenBank accession no NC008275) has been used to design the degenerate primers to amplify $x y l M$ gene. Sequence of these primers are, xylQ F 5' GGCCATATGAGCAAGAAACTC 3, xylQ R 5' CGATGTCGGCGAATTCGGGC 3', xylM F 5' GAT GCC TTC GCT CTT TGT GT 3', xylM 5' GAT GCC TTC GCT CTT TGT GT 3'. Plasmid DNA templates of Alcaligenes faecalis, Alcaligenes sp. DN25, Bacillus methilotrophicus and Bacillus cereus were amplified using above primers. Then PCR products were visualized and their size estimation was done by gel electrophoresis.

\section{Sequencing of PCR products}

Automated sequencing was carried out using applied Biosystems automated sequencer (ABI3730XL) at Macrogen, Seoul, Korea. Purified PCR products of $x y l M$ and $x y l Q$ gene segments were sequenced directly using appropriate primers.

\section{Restriction digestion of PCR products}

PCR amplicons of $x y l M$ and $x y l Q$ genes were digested using HindIII restriction enzyme to determine their RFLP patterns.

\section{Results}

According to the Undugoda et al. [2], A. faecalis, Alcaligenes sp. DN25, B. methylotrophicus and B. cereus were the best toluene and xylene degraders isolated from the selected four plant species inhabit the five poluted sites of Sri Lanka. Plasmid isolation and ampicillin resistancy test of all four bacterial strains revealed they haboured plasmids. To check whether this toluene and xylene degrading ability is a plasmid encoded or not plasmid transformation and plasmid curing process was done. Eventhough according to the gel electrophoresis results (Figure 1) transformation of plasmids of Alcaligenes feacalis (plasmid 1) and Alcaligenes sp. DN25 (plasmid 2) into E. coli JM109 was successful, it was unable to transform plasmids of B. cereus (plasmid 3) and B. methylotrophicus (plasmid 4) in to E. coli JM109 successfully.

According to the HPLC analysis results E. coli JM109 was unable to degrade toluene and xylene efficiently. But after getting plasmid 1 and plasmid 2 into E. coli JM109, it was able to degrade toluene and xylene almost close to the plasmid harboured original bacterial strains, Alcaligenes faecalis and Alcaligenes sp. DN25 (Figure 2). In fact, Alcaligenes feacalis was able to degrade $63.64 \%$ of xylene in the medium and E. coli JM109 transformants with plasmid of Alcaligenes faecalis was able to degrade $50.95 \%$ of xylene in the medium. These results convinced toluene and xylene degradation ability of $A$. feacalis and Alcaligenes sp. DN25 is a plasmid encoded character. It was again confirmed by curing the plasmids of transformant using SDS treatment.

After curing the plasmids of transformants, toluene and xylene degrading ability of them were lost. HPLC results revealed after the curing process, xylene degrading ability of plasmid 1 harboured $E$. coli JM109 was declined into $2.01 \%$ (Figure 3). As well as their toluene degradation ability was declined into $1.54 \%$ (Figure 4 ). These results convince toluene and xylene degradation ability is encoded by the plasmids located in these efficient phyllosphere degraders, $A$. faecalis and Alcaligenes sp. DN25.

Transformation and plasmid curing results confirmed xylene and

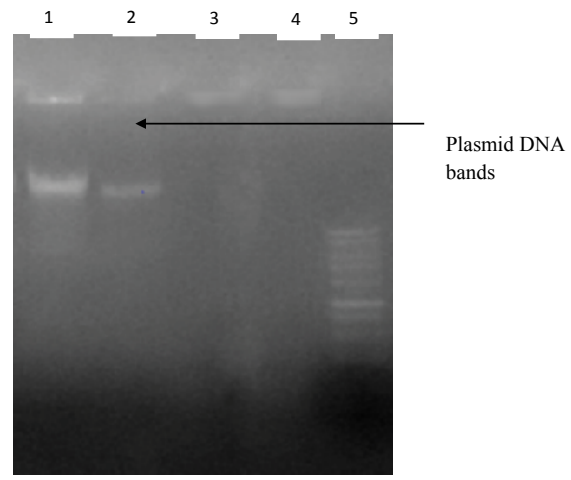

Figure 1: Gel electrophoresis of plasmid DNA from E. coli, JM109, transformants. Lane 1. Plasmid DNA of $A$. faecalis, transformed into $E$. coli JM109 Lane 2. Plasmid DNA of Alcaligenes sp. DN25 transformed into $E$. coli JM109 Lane 3. Plasmid DNA of $B$. cereus transformed into $E$. coli JM109, Lane 4. Plasmid DNA of $B$. methylotrophicus transformed into E. coli JM109 Lane 6. Lamda Hind III ladder.

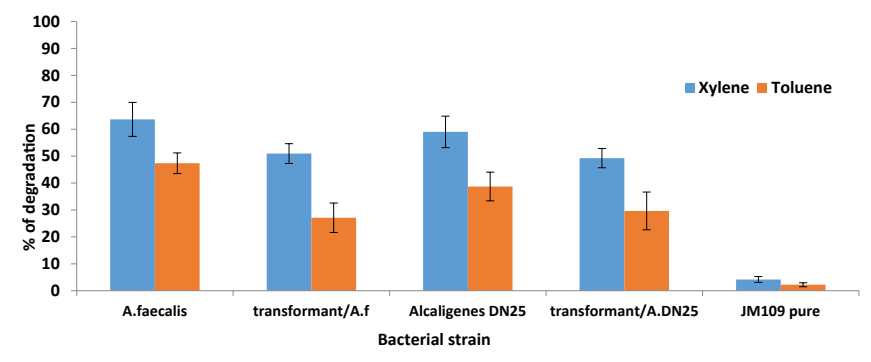

Figure 2: $\mathrm{AH}$ degradation (\%) by two Alcaligenes sp. and two E. coli strains transformed with plasmids from two Alcaligenes spp. as assayed by HPLC method. $\mathrm{N}=6$. 
Citation: Undugoda LJS, Kandisa RV, Kannangara S, Sirisena DM (2018) Plasmid Encoded Toluene and Xylene Degradation by Phyllosphere Bacteria. J Environ Anal Toxicol 8: 559. doi: 10.4172/2161-0525.1000559

Page 3 of 4

toluene degradation ability of these phyllosphere bacteria, Alcaligenes feacalis and Alcaligenes sp. DN25 is a plasmid encoded character. Though transformation and plasmid curing of $B$. cereus and $B$. methylotrophicus were unsuccessful, they showed higher toluene and xylene degradation ability as those two Alcaligenes sp. Therefore, PCR amplification was done using $x y l Q$ and $x y l M$ specific primers to check, whether these xylene and toluene degrading genes are located on the plasmids isolated from $\mathrm{AH}$ degrading four phyllosphere bacterial species. 654 bp size PCR amplicons were observed with plasmid DNA templates of Alcaligenes sp. DN25, Alcaligenes feacalis and Bacillus cereus (Figure 5). This gel electrophoresis results revealed except $B$. methylotrophicus, other three bacterial strains haboured $x y l Q$ gene in their plasmids.

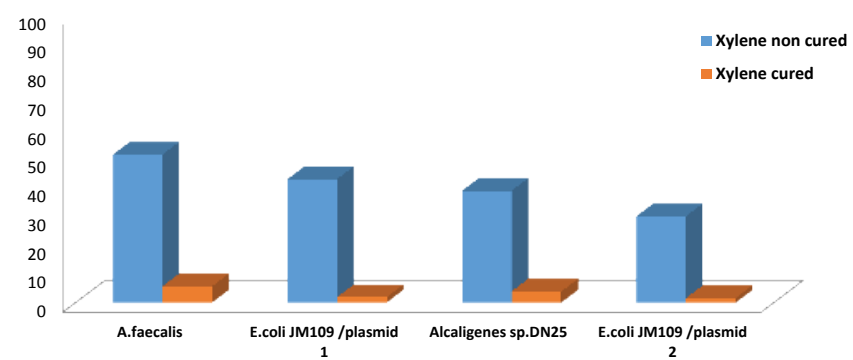

Figure 3: Percentage of xylene degradation by each bacterial strain, before and after curing of plasmid as assayed by colorimetric method. $\mathrm{N}=6$.

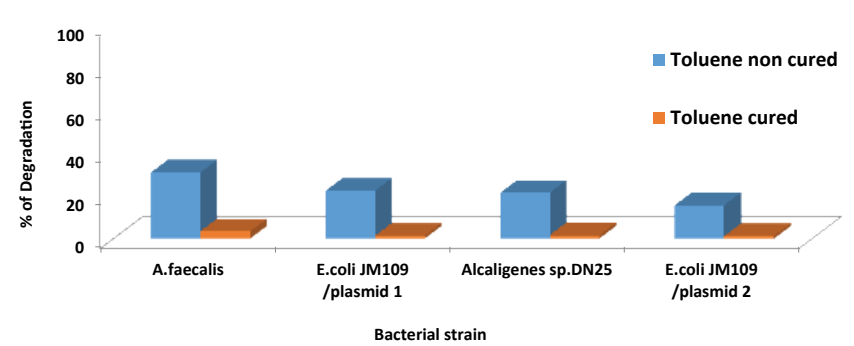

Figure 4: Percentage of toluene degradation by each bacterial strain, before and after curing of plasmid as assayed by colorimetric method. $\mathrm{N}=6$.

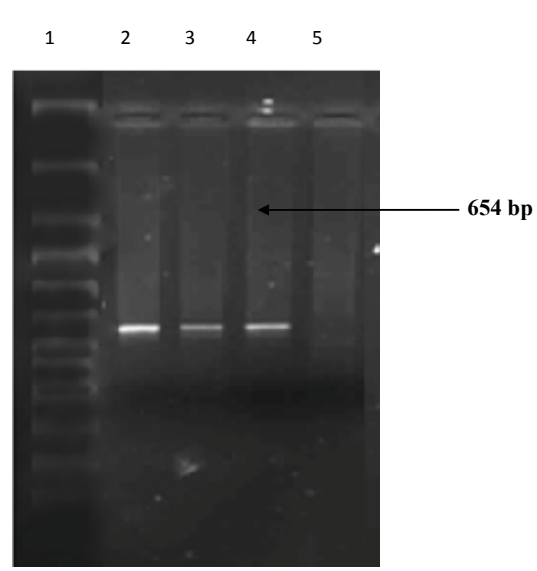

Figure 5: Gel electrophoresis of PCR products obtained by amplification of plasmid DNA templates with primers $x y l Q$ for gene $x y / Q$. Lane 1- Lambda HindIII ladder, Lane 2- Alcaligenes faecalis, Lane 3- Alcaligenes sp. DN25, Lane 4 -Bacillus cereus, Lane 5- B. methylotrophicus.
Partial nucleotide sequence of $x y l Q$ gene of Alcaligenes feacalis showed $83 \%$ similarity to the $x y l Q$ gene located in the pDK1 plasmid of $P$. putida. Nucleotide sequence of $x y l Q$ gene of Alcaligenes sp. DN25 showed $85 \%$ similarity to the $x y l Q$ gene located in the $\mathrm{pWW} 53$ plasmid of P. putida MT53. Nucleotide sequence of $x y l Q$ gene of Bacillus cereus showed $98 \%$ similarity to the $x y l Q$ gene located in the pNL1A plasmid of Sphingomonas aromaticiviran. Both Alcaligenes sp. showed higher similarity with same gene located in the plasmids of Pseudomonas sp.

The same gene in different organisms may exist as different alleles with slight variations in their nucleotide sequence. Specially, the catabolic genes are highly variable due to the harsh conditions in the environment. Therefore, the same catabolic gene has so many different alleles. These genetic variations can be used to identify genetic relationships among phyllosphere microorganisms. Therefore, RFLP patterns and nucleotide sequences of these catabolic genes were used to determine phylogenetic relationships existing among $\mathrm{AH}$ degrading phyllosphere bacterial strains. The $x y l Q$ gene amplicon obtained from PCR was digested with HindIII enzyme and RFLP pattern of $x y l Q$ gene was visualized using gel electrophoresis (Figure 6).

HindIII digestion of $x y l Q$ gene gave two distinct RFLP patterns between Bacillus sp. and Alcaligenes sp. However, RFLP pattern of Alcaligenes faecalis and Alcaligenes sp. DN25 was similar to each other (Figure 5). But RFLP patterns of Alcaligenes sp. and Bacillus sp. are significantly different to each other. In fact, $x y l Q$ gene of Alcaligenes sp. was digested into two DNA fragments by HindIII, but $x y l Q$ gene of Bacillus sp. was digested into three DNA fragments. Therefore, same gene has different number of restriction sites. It reveals that the same gene has different alleles when they exist in different genera of phyllosphere bacteria. But the particular gene is homologous within similar species. Therefore, the plasmid harbored xylene degrading phyllosphere bacterial strains have two different allele types of $x y l Q$ gene.

\section{Discussion}

The TOL plasmid pWWO of Pseudomonas putida mt-2 is a 117-kilobase $(\mathrm{kb})$ catabolic plasmid which has ability to encodes all enzymes necessary for bacterial utilization of toluene (Tol), $\mathrm{m}$ - and p-xylene (Xyl), 3-ethyltoluene, and 1,2,4-trimethylbenzene and carboxylic acid derivatives, via a meta cleavage pathway [8]. Most

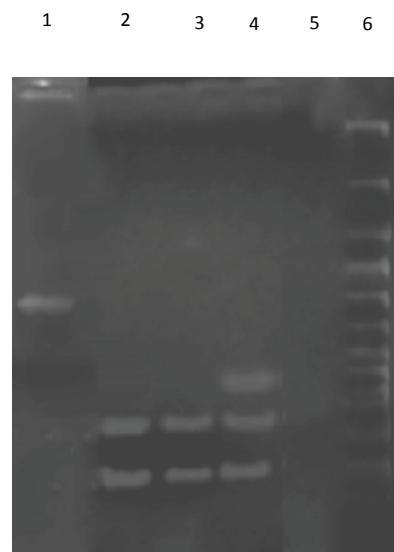

Figure 6: Gel electrophoresis of digested $x y / Q$ gene fragment containing PCR product, Lanes 1 - Non digested $654 \mathrm{bp} x \mathrm{IQ}$ PCR product from $A$. faecalis, Lane 2-digested PCR product from Alcaligenes sp. DN25, Lane 3 - digested PCR product from Alcaligenes faecalis, Lane 4- Digested PCR product from Bacillus cereus, Lane 6 - molecular weight marker (100-bp ladder). 
Citation: Undugoda LJS, Kandisa RV, Kannangara S, Sirisena DM (2018) Plasmid Encoded Toluene and Xylene Degradation by Phyllosphere Bacteria. J Environ Anal Toxicol 8: 559. doi: 10.4172/2161-0525.1000559

Page 4 of 4

often Pseudomanas sp. was able to degrade toluene and xylene and degradation ability of them were plasmid encoded character. But in this study the best toluene and xylene degraders were two Alcaligenes spp. and their degradation is a plasmid encoded character. Even though two Bacillus sp. were harbored plasmids and degrade toluene and xylene, it was unable to determine it as a plasmid encoded character due to the unsuccessful transformation and curing process. But PCR amplification results of $B$. cereus revealed it has $x y l Q$ gene located on its plasmid.

Many genes responsible for the $\mathrm{AH}$ degradation are located on the plasmids. Nevertheless, some genes are located on the chromosome of the bacteria. Occasionally, such genes are genomic based and their regulatory genes are plasmid based. Then, plasmid or chromosomal genes cannot express AH degrading character autonomously [1]. The catabolic plasmids which encode the enzymes to initiate pathways for the catabolism of toluene, $\mathrm{m}$-xylene, and $\mathrm{p}$-xylene via aromatic ring meta cleavage is referred to as TOL plasmids [5]. TOL plasmids have mostly been found in representatives of the genus Pseudomonas. As an example, pWWO plasmid of $P$. putida harbored $x y l$ genes which encoded the xylene and toluene degrading enzymes [9]. Besides toluene degradation, this plasmid has been shown to mediate the degradation of $\mathrm{m}$ - and p-toluate, $\mathrm{m}$ - and $\mathrm{p}$-xylene and related compounds [4] to acetaldehyde and pyruvate via a bifurcating pathway. Furthermore, the plasmids pWW53, pDK1, and pWW15 also located in Pseudomonas sp. which carried many $x y l$ genes [10]. But phyllosphere samples collected from five polluted sites were rich in Alcaligenes sp. and their plasmidencoded toluene and xylene degradation ability was high. Nucleotide sequence of $x y l Q$ gene of both of these Alcaligenes sp. had more than $80 \%$ sequence similarity to the $x y l Q$ gene harboring plasmids of Pseudomonas sp. Therefore, there should be close phylogenetic relationship among the $x y l Q$ gene of Alcaligenes sp. and $x y l Q$ gene of Pseudomonas sp.

Bacillus cereus isolated in this work harbored $x y l Q$ gene on its catabolic plasmid and it was able to degrade these AHs efficiently. Although, most of the $x y$ l genes carrying catabolic plasmids are found in Gram negative bacterial strains, Bacillus cereus, a Gram positive strain also has $x y l$ gene on its plasmid. The catabolic plasmids of Alcaligenes faecalis, Alcaligenes sp. DN25 and Bacillus cereus harbored xylQ genes and they lack $x y l M$ genes. RFLP patterns of PCR amplified $x y l Q$ gene segment revealed Alcaligenes feacalis and Alcaligenes sp. DN25 had same RFLP pattern of $x y l Q$ gene and this pattern is different from RFLP pattern of $x y l Q$ gene of Bacillus cereus (Figure 5). When same gene locates in same genus, they are similar to each other controversy when it locates in the plasmids of different genus, they are different to each other. Therefore same $x y l Q$ gene has two different alleles.

\section{Conclusion}

Toluene and xylene degradation ability of $A$. faecalis and Alcaligenes sp. DN25 is a plasmid encoded character. XylQ genes of them were located in their catabolic plasmids. Out two AH degrading Bacillus sp. (Bacillus methylotrphicus and B. cereus) B. cereus harbors $x y l Q$ gene on its catabolic plasmid. XylQ gene of two Alcaligenes spp was different from that of Bacillus cereus. That mean $x y l Q$ gene has two allele types when they exist in the environment.

\section{References}

1. Andrew AS, Karagas MR, Hamilton JW (2003) Decreased DNA repair gene expression among individuals exposed to arsenic in United States drinking water. International Journal of Cancer 104: 263-268.

2. Undugoda LJ, Kannangara S, Sirisena DM (2016) Aromatic Hydrocarbon Degrading Fungi Inhabiting the Phyllosphere of Ornamental Plants on Roadsides of Urban Areas in Sri Lanka. J Bioremed Biodeg 7: 2.

3. Gallegos MT, Marqués S, Ramos JL (1996) Expression of the TOL plasmid xylS gene in Pseudomonas putida occurs from a alpha 70-dependent promoter or from alpha 70-and alpha 54-dependent tandem promoters according to the compound used for growth. Journal of Bacteriology 178: 2356-2361.

4. Worsey MJ, Williams PA (1975) Metabolism of toluene and xylenes by Pseudomonas (putida arvilla) mt-2: evidence for a new function of the TOL plasmid. Journal of Bacteriology 124: 7-13.

5. Assinder SJ, Williams PA (1990) The TOL plasmids: determinants of the catabolism of toluene and the xylenes. Advances in Microbial Physiology 31 : 1-69.

6. Aemprapa S, Williams PA (1998) Implications of the xylQ gene of TOL plasmid pWW102 for the evolution of aromatic catabolic pathways. Microbiology 144 1387-1396.

7. Sambrook J, Fritsch EF, Maniatis T (1989) Molecular cloning: A laboratory manual. 2nd edn. Cold Spring Harbor Laboratory Press. Cold Spring Harbor, NY, USA.

8. Zylstra GJ, McCombie WR, Gibson DT, Finette BA (1988) Toluene degradation by Pseudomonas putida F1: genetic organization of the tod operon. Applied and Environmental Microbiology 54: 1498-503.

9. Williams PA, Murray K (1974) Metabolism of benzoate and the methylbenzoates by Pseudomonas putida (arvilla) mt-2: evidence for the existence of a TOL plasmid. Journal of Bacteriology 120: 416-423.

10. Keil H, Keil S, Williams PA (1987) Molecular analysis of regulatory and structural xyl genes of the TOL plasmid pWW53-4. Microbiology 133: 1149-1158. 